\title{
Adrenal Incidentaloma: A Diagnostic Dilemma
}

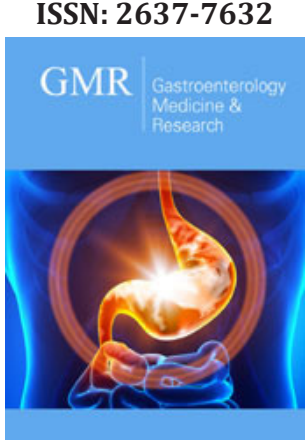

*Corresponding author: Arcelia Guerson Gil, MD, Internal Medicine, Jacobi Medical Center, USA

Submission: 韭 February 14, 2020

Published: 帮February 24, 2020

Volume 4 - Issue 3

How to cite this article: Arcelia Guerson Gil, Pawan Rastogi, Saeed Asiry, Sammy Ho. Adrenal Incidentaloma: A Diagnostic Dilemma.Gastro Med Res. 4(3). GMR.000587. 2020.

DOI: $10.31031 /$ GMR.2020.04.000587

Copyright@ Arcelia Guerson Gil, This article is distributed under the terms of the Creative Commons Attribution 4.0 International License, which permits unrestricted use and redistribution provided that the original author and source are credited.

\author{
Arcelia Guerson Gili ${ }^{1 *}$, Pawan Rastogi ${ }^{2}$, Saeed Asiry ${ }^{3}$ and Sammy Ho ${ }^{4}$ \\ ${ }^{1}$ Internal Medicine, Jacobi Medical Center, USA \\ ${ }^{2}$ Gastroenterology, Montefiore Medical Center, USA \\ ${ }^{3}$ Pathology, Montefiore Medical Center, USA \\ ${ }^{4}$ Gastroenterology, Montefiore Medical Center, USA
}

\section{Abstract}

Adrenal incidentalomas (AI) are most commonly harmless detected through imaging procedures done for unrelated reasons. Some, if left untreated can have significant consequences. This in turn poses for the caring physician a dilemma as to whether or not to pursue a biopsy. As of now, surgery has been the only feasible diagnostic approach. Here, AI was successfully biopsied via EUS-FNA, which resulted in diagnostic yield. This case is important in that it highlights the use of endoscopic ultrasonography (EUS) with fine needle aspiration (FNA) as an alternative modality.

Keywords: Adrenal incidentaloma; EUS-FNA; Malignancy; Endoscopic ultrasonography; Fine needle aspiration

\section{Introduction}

Adrenal incidentalomas (AI) are most commonly benign and hormonally inactive, detected through imaging procedures done for unrelated reasons. The challenge is recognizing and treating the small percentage of AI that do pose a significant risk, either because of their malignant potential or because of their hormonal activity. We present an interesting case where an AI suspicious for metastatic disease was successfully biopsied by endoscopic ultrasonography (EUS) with fine needle aspiration (FNA).

\section{Case Presentation}

71-year-old African American woman recently diagnosed with poorly differentiated invasive ductal carcinoma of the left breast was found to have a $2 \mathrm{~cm}$ left adrenal nodule on abdominal CT scan raising concern for metastasis (Figure 1). While the patient remained largely asymptomatic, discussion at our institution's Multidisciplinary Tumor Board resulted in continued suspicion for a metastatic process. The gastroenterology team was then involved, and an EUS was conducted, revealing a round hypoechoic lesion in the left adrenal gland (Figure 2). FNA for cytology was successfully performed with cytology results being negative for malignant cells. Further, immunohistochemical staining confirmed benign adrenocortical tissue (Figure 3).

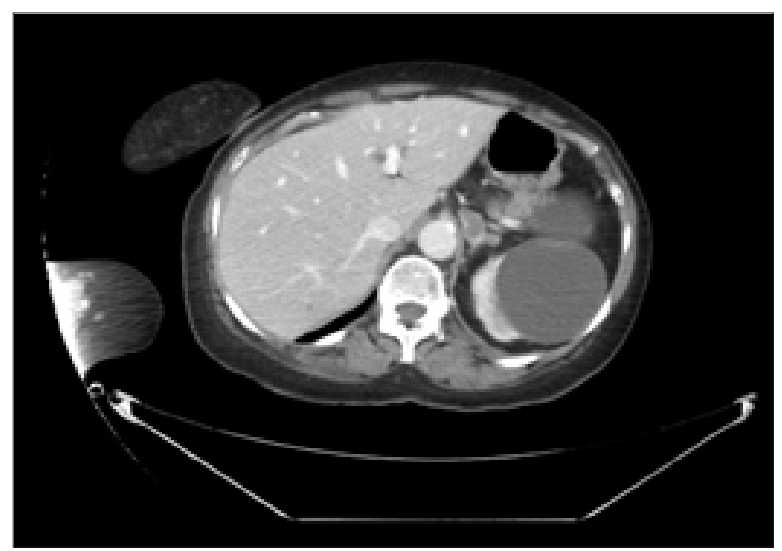

Figure 1: Contrast-enhanced computed tomography (CT) showed a new $2.5 \times 1.5 \mathrm{~cm}$ left adrenal nodule. 


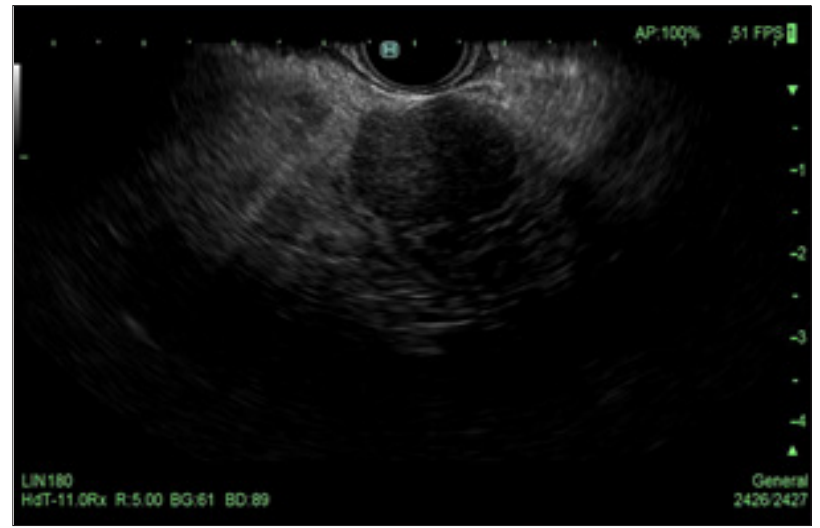

Figure 2: A round hypoechoic mass was identified endosonographically in the left adrenal gland. The mass measured $25 \mathrm{~mm}$ in maximal cross-sectional diameter. Borders were well-defined.

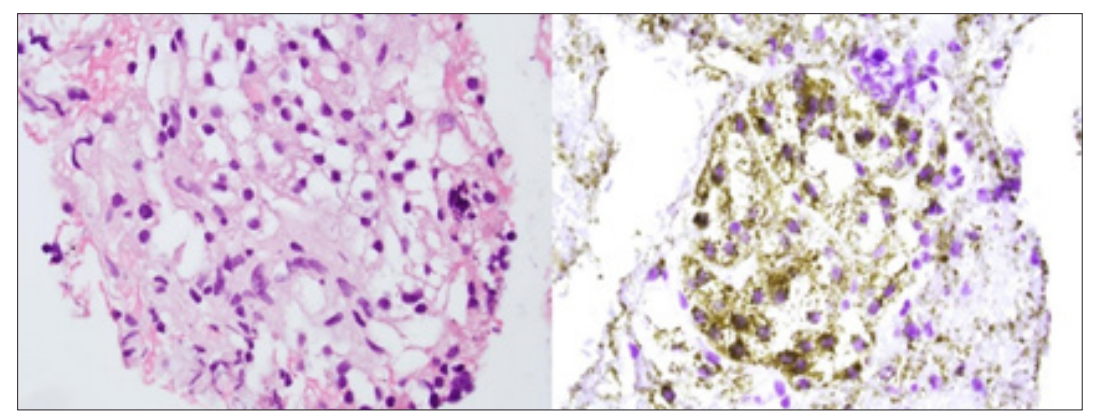

Figure 3: (Left) Adrenal EUS-FNA (Cell block): High power view (400X) of benign adrenocortical cells with bland round to oval nuclei and vacuolated cytoplasm. (Hematoxylin and Eosin stain) (Right) Adrenal EUS-FNA (Cell block): High power view (400X) of benign adrenocortical cells with Melan-A positive cytoplasmic granular staining. (Immunohistochemistry).

\section{Discussion}

Although most AI are harmless, some, if left untreated may lead to significant pathological processes [1]. This, in turn, proposes a dilemma for the physician as to whether or not to pursue a biopsy. Obtaining tissue diagnosis results in a significant burden on the overall health care system. Furthermore, a high probability exists that biopsy results may not alter the overall management of patient's care. On the other hand, failure to identify a malignancy (or metastasis in our case) can be detrimental to the patient's care. Prior studies have suggested that advanced age is associated with increasing frequency of adrenal masses, ranging from $<1 \%$ among individuals less than 30 years of age to about $7 \%$ in those 70 years of age or older [2]. The optimal strategy for hormonal screening of a patient with $\mathrm{AI}$ is unknown. Up to this point, surgery has been the only definitive diagnostic and therapeutic approach [3]. Here we present a case where AI was successfully biopsied via EUS-FNA, resulting in diagnostic yield. This case highlights the use of EUSFNA as an alternative modality, and effective middle ground, for the evaluation of AI.

\section{References}

1. Georg M, Lau J, Balk E, Rothberg M, Miyachi Y, et al. (2004) The clinically inapparent adrenal mass: Update in diagnosis and management. Endocrine Reviews 25(2): 309-340.

2. Kloos RT, Gross MD, Francis IR, Korobkin M, Shapiro B (1995) Incidentally discovered adrenal masses. Endocrine Reviews 16(4): 460-84.

3. Luisa B, Sonino N, Fallo F, Palu G, Boscaro M (2003) Prevalence and natural history of adrenal incidentalomas. European Journal of Endocrinology 149(4): 273-85. 